\title{
Integrated Research for Integrated Ocean Management
}

\author{
Lena Rölfer ${ }^{1,2 *}$, Arianna Liconti ${ }^{3,4}$, Natalie Prinz $^{5}$ and Clara Antonia Klöcker 6 \\ ${ }^{1}$ Faculty of Sustainability, Leuphana University, Lüneburg, Germany, ${ }^{2}$ Climate Service Center Germany (GERICS), \\ Helmholtz-Zentrum Hereon, Hamburg, Germany, ${ }^{3}$ The Marine Biological Association, The Laboratory, Plymouth, \\ United Kingdom, ${ }^{4}$ Outdoor Portofino, Genova, Italy, ${ }^{5}$ School of Science, University of Waikato, Tauranga, New Zealand, \\ ${ }^{6}$ Institute of Environmental Engineering (IfU), Eidgenössisch Technische Hochschule (ETH), Zurich, Switzerland
}

With the start of the United Nations (UN) Decade of Ocean Science for Sustainable Development in 2021, research priorities to support the sustainable use of coastal and ocean resources and their conservation are in the spotlight. However, to date comprehensive regulation and management of multifaceted and multi-used ecosystems has proven challenging. This is partly due to the complexity of coastal and ocean socialecological systems (SES), as well as the multitude of approaches to manage those spaces. In order to address such challenges, magnified by often-conflicting interests between economic activities and nature conservation, there is an urgent need for integrated approaches that bridge the gap between science, policy and society, as well as across different epistemological boundaries set by various management approaches.

OPEN ACCESS

Edited by:

Simon Jungblut,

University of Bremen, Germany

Reviewed by:

John Virdin,

Duke University, United States

Carmen E. Elrick-Barr,

University of the Sunshine Coast,

Australia

${ }^{*}$ Correspondence:

Lena Rölfer

lena.roelfer@hereon.de

Specialty section:

This article was submitted to Global Change and the Future Ocean,

a section of the journal

Frontiers in Marine Science

Received: 10 April 2021

Accepted: 19 July 2021

Published: 17 August 2021

Citation:

Rölfer L, Liconti A, Prinz N and Klöcker CA (2021) Integrated Research for Integrated Ocean Management.

Front. Mar. Sci. 8:693373. doi: 10.3389/fmars.2021.693373
Consequently, the interest in multi-, inter-, and transdisciplinary research approaches at the national and international levels has been growing. In light of the recently started Decade of Ocean Science, this paper aims at providing key considerations for research approaches that tackle the outlined challenges in managing the ocean space. From a survey targeted at projects and initiatives that apply multi-, inter-, and transdisciplinary approaches, we draw examples of challenges and good-practices. Based on this, we propose three key considerations for an integrated research approach, including (1) target setting, resource management, and adaptive planning; (2) knowledge production and responsiveness toward policy and society; and (3) co-design, co-development, cooperation, as well as effective communication. The considerations laid out in this paper are aimed at the effective translation between science, policy, and society in support of sustainable coastal and ocean governance within the Decade of Ocean Science.

Keywords: science-policy interface, ocean action, science communication, social-ecological systems, interdisciplinarity, transdisciplinarity, ocean literacy, conservation

\section{INTRODUCTION}

People's perception of the ocean has changed particularly throughout the last decade. More attention and awareness within society are created around "Our Blue Planet" (referring to the equally named BBC series), e.g., throughout (social) media, citizen science (e.g., Earp and Liconti, 2019), and ocean literacy initiatives (Drakou et al., 2017). Furthermore, the ocean and its governance have been increasingly put on the agenda of international policy meetings, including various actors from science, governments, non-governmental institutions, and the private sector 
(Campbell et al., 2016). There is increasing awareness that the ocean presents an integral part in the earth's system and successive recognition of ocean systems providing valuable services sustaining human livelihood, well-being, and economic development. Coastal and ocean ecosystem services, such as the provision of resources, energy, carbon sequestration and tourism, contribute to a global estimated value of $>2.5$ trillion US\$ (Costanza et al., 2017), providing food to 3 billion people, and transporting $90 \%$ of world trade through the ocean (WWF, 2015). These growing economic activities are commonly referred to as the Blue Economy (Voyer et al., 2018). Its rapid increase was recently termed the "Blue Acceleration" (Jouffray et al., 2020), which also describes the pace at which coastal and ocean systems are altered. Despite the increasing awareness for the services the ocean provides to humankind, related human activities are contributing to the persisting degradation of coastal and ocean ecosystems. Respective environmental issues include, but are not limited to, climate change, the overuse of natural resources, alien species, (plastic) pollution, eutrophication, and sedimentation (IPCC, 2019; Jouffray et al., 2020).

The year 2020 presented a benchmark for many international policy goals and targets linked to ocean health. The EU Water Framework Directive, for example, has called for "Good Environmental Status" to be reached by 2020 (European Commission, 2008), the United Nations (UN) Aichi Biodiversity Target 11 aimed at protecting at least $10 \%$ of the global ocean by 2020 (Convention on Biological Diversity, 2010), and several Sustainable Development Goal (SDG) sub-targets aimed at conservation and sustainable use of the oceans, seas and ocean resources for sustainable development by 2020 (e.g., SDG 14.2 sustainably manage and protect coastal and ocean ecosystems to avoid significant adverse impacts; 14.4 effectively regulate harvesting and end overfishing and IUU fishing; 14.6 harmful subsidies). Due to the current COVID-19 pandemic, reviews and renewal of commitments for international agreements such as the Aichi Biodiversity Targets have been delayed to 2021. However, according to the Global Biodiversity Outlook 5, no single target has been met by 2020 (European Environment Agency, 2020; Secretariat of the Convention on Biological Diversity, 2020; WWF, 2020). In early 2021, only $6.4 \%$ of the ocean's surface is formally protected through marine protected areas (MPAs), while an additional $<1 \%$ is designated and further $1.4 \%$ are proposed, yet not implemented (Marine Conservation Institute, 2021). Even when considering all proposed areas, a maximum of $8.4 \%$ is designated for protection, which falls short of the arguably low target for protection of $10 \%$. The protection of biodiversity in areas beyond national jurisdiction $(\mathrm{ABNJ})$ is only emerging (see Box 1) and currently negotiated under UNCLOS (United Nations Convention on the Law of the Sea).

Moving toward a more sustainable and resilient ocean requires an improved translation of intergovernmental agreements such as the SDGs, Aichi Biodiversity Targets, and the Paris Climate Agreement into locally relevant action (UN, 2021). Various means exist that are aimed at the sustainable management of marine resources, including ecosystem-based management $(\mathrm{EbM})$, local to regional planning processes such as Integrated Coastal Zone Management (ICZM), and Marine Spatial Planning
(MSP), and a variety of other area-based management (ABM) approaches, including MPAs (Figure 1) (Winther et al., 2020; Dunstan et al., 2021). Such means are adaptive in order to adjust to changing conditions and new knowledge for constantly improving management policies and practices (Katona et al., 2017; Winther et al., 2020). EbM is defined as "an integrated approach to management that considers the entire ecosystem, including humans" (McLeod et al., 2005). It is widely agreed upon as an effective and integrated approach to planning and management and aims at maintaining an ecosystem in a healthy, productive, and resilient condition for the provisioning of services to humans. It provides a holistic approach that goes beyond examining sectors, habitats, or ecosystem functions in isolation. Instead, it recognizes ecological systems as a set of rich and complex actors and processes, which are strongly interdependent. EbM considers the increasing role of humans and acknowledges that human welfare and the health of the environment are strongly linked (Tallis et al., 2010; Long et al., 2015).

While EbM is generally acknowledged as a meaningful tool for $\mathrm{ABM}$, there are still issues with the implementation of different approaches at multiple scales. First, coastal and ocean socialecological systems (SES) are complex, including interactions and dynamics across epistemological, geographical, and institutional boundaries (Neumann et al., 2017), which are concurrently set by such ABM approaches. Second, adaptive management also needs to integrate knowledge about uncertain future drivers (Brown et al., 2014; Chakraborty et al., 2020; Weise et al., 2020). Particularly, the integration of climate change has been challenging to date (Tobey et al., 2010; Frazão Santos et al., 2020; Gissi et al., 2021). Third, given the vastness of coastal and ocean ecosystems, an institutional fragmentation of governance and management activities predominates (Nursey-Bray et al., 2014; Campbell et al., 2016; Cumming and Peterson, 2017; de Alencar et al., 2020). This fragmentation is particularly pronounced in these systems, as the implementation of EbM via different $\mathrm{ABM}$ approaches varies among responsible authorities and across regions and nations, from global to local level (Boyes and Elliott, 2014). The governance of coastal and ocean systems is hence perceived as a "complex, non-linear, and confusing policyscape" (O’Hagan et al., 2020).

Given the extent of tools, approaches, and processes that govern the ocean space, as well as the concurrent need to view it as an integrated SES, the demand for more holistic approaches, such as "Integrated Ocean Management" (IOM), has gained awareness in recent years (Diz et al., 2018; Rudolph et al., 2020; Stojanovic and Gee, 2020; Winther et al., 2020). IOM can be defined as "a holistic, ecosystem-based, and knowledge-based approach to planning and managing the use of ocean space, with the goal of balancing various uses and needs to achieve a sustainable ocean economy along with healthy ecosystems" (Winther et al., 2020). Alongside knowledge about the ecological processes in coastal and ocean systems, it specifically recognizes the role - as well as issues - of humans and their agency in form of actors involved in, the scale of, and knowledge informing their governance (Campbell et al., 2016). The engagement of actors with often diverse interests 
BOX 1 | Managing the "last conservation frontier" in areas beyond national jurisdiction.

Governance has long focused on coastal shelf areas, which are subject to national jurisdiction (see Figure 1). While national waters cover only $39 \%$ of the ocean area of which $17.3 \%$ are designated as MPAs, only $1.2 \%$ of areas beyond national jurisdiction (ABNJ) have been established as protected areas (UNEP-WCMC et al., 2018). Yet, while this domain has long been considered "dangerous and dark," it has become increasingly accessible and, as with other commons free to access, over-utilized. Already in the 1950s, fishing grounds were extended beyond $200 \mathrm{~nm}$ and in subsequent decades catches from the ABNJ increased by a factor of more than 10, resulting in overfishing and rapid biodiversity declines in vulnerable marine ecosystems (Dunn et al., 2018). Growing interests in deep-sea metals and marine genetic resources further challenge the current regime governing ABNJ, which so far presents a patchwork of attempts to regulate resource extraction (Tiller et al., 2019). EbM approaches, including a representative system of comprehensive MPAs that protect the full range of species and habitats in ABNJ, fall outside the scope of any single sector-specific or conservation agreement (Ardron et al., 2014).

To fill the prevailing void of a comprehensive ocean governance regime in ABNJ, the United Nations General Assembly (UNGA) launched an intergovernmental conference in 2017 (Resolution 72/249) with the mandate of negotiating a new international legally binding instrument under UNCLOS, aimed at the conservation and sustainable use of biodiversity beyond national jurisdiction (BBNJ) (Tiller et al., 2019). In this process, area-based management tools (ABM tools) such as MPAs in combination with environmental assessments were identified as the two key management tools for achieving "coordinated implementation of EbM approaches by sectoral bodies and states" (Ardron et al., 2014). Further, the current draft encompasses a chapter on capacity building and marine technology transfer as well as marine genetic resources including respective benefit sharing. However, there are still many open questions and underlying conflicts dominating the BBNJ negotiations. A prevalent issue centers around the question on how to create a powerful instrument without undermining competences of existing instruments, which constitute the primary authorities, e.g., to designate ABM tools (Scanlon, 2018). Another line of divergence lies in the different perceptions on what "science-based approaches" and the use of "best available science" mean in the BBNJ context. Many stakeholders seem to agree on the benefits of integrated management, issues pertaining to the trustworthiness and credibility of science, as well as the application of precautionary approaches given data insufficiency. Yet, perceptions diverge regarding the definition, status, or authority of "science" in the BBNJ process and the extent to which conservation or sustainable use goals are emphasized (Gaebel et al., 2020).

The slow progress in the BBNJ negotiations, which have started already in 2004, may thus reflect the inherent difficulty of implementing a cross-sectoral and science-based approach, which moves beyond sector- or area-specific protection measures, in a setting which is transboundary in nature. As the finalization of the BBNJ negotiations is still outstanding, there remains a window of opportunity to apply the lessons learned and overcome the sectoral and national interest-driven thinking, for preserving the Earth's "last conservation frontier" (Gjerde et al., 2016).

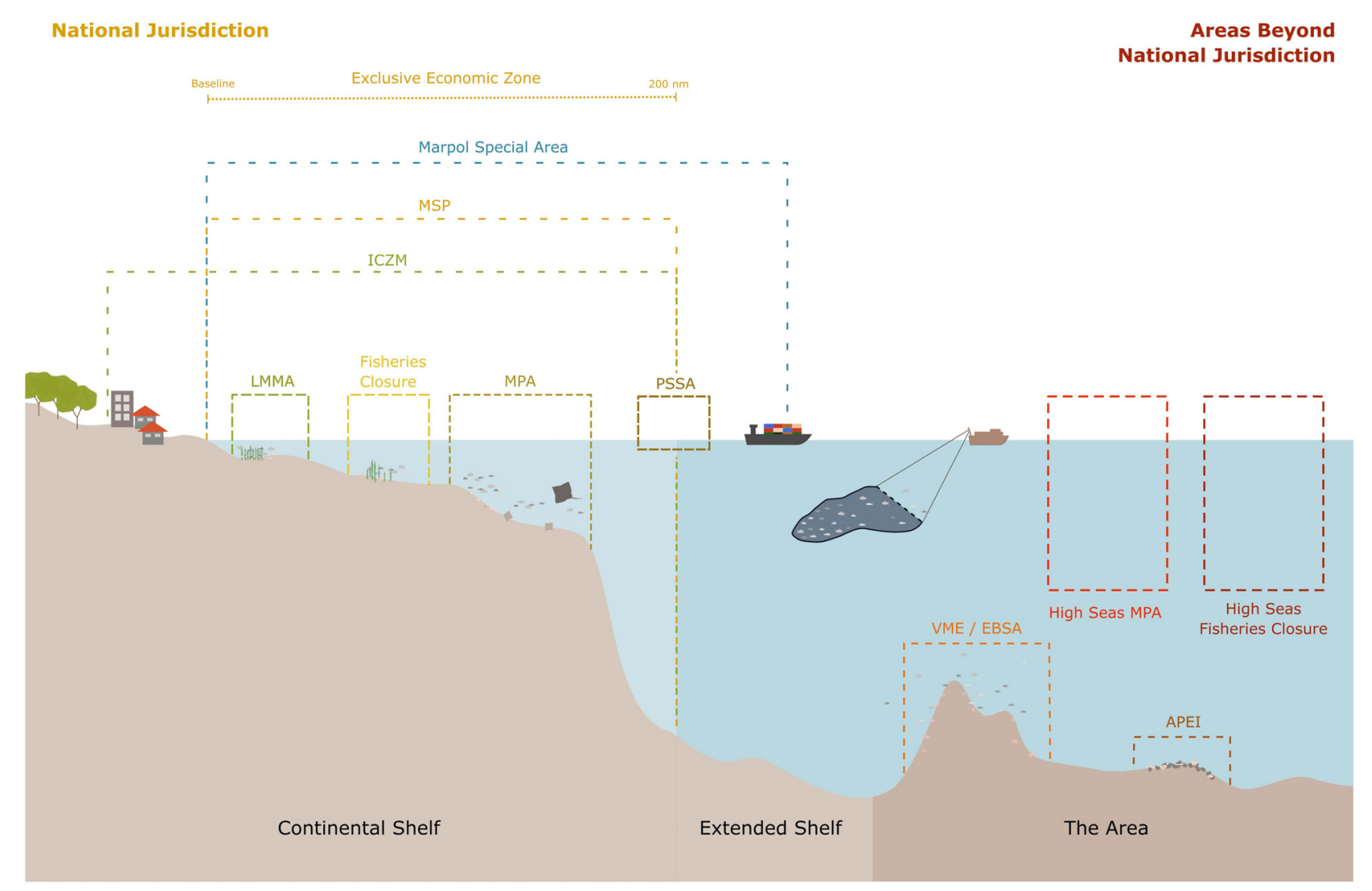

FIGURE 1 | Illustrative spatial coverage of various area-based management approaches for areas within and beyond national jurisdiction, as well as respective international management bodies (modified from UN Environment, 2018). MSP, Marine Spatial Planning; ICZM, Integrated Coastal Zone Management; LMMA, Locally Managed Marine Area; MPA, Marine Protected Areas; PSSA, Particularly Sensitive Sea Area (IMO, International Maritime Organization); VME, Vulnerable Marine Ecosystem (FAO, Food and Agriculture Organization; RFMOs, Regional Fisheries Management Organisations); EBSA, Ecologically or Biologically Significant Area (CBD, United Nations Convention on Biological Diversity); APEI, Areas of Particular Environmental Interest (ISA, International Seabed Authority). 
has gained importance and should include stakeholders from a variety of sectors from local to international scale (Jones et al., 2016), including communities, governments, businesses, and civil society organizations (Celliers et al., 2020). An integrated approach between multiple area-based management approaches as well as different sectors may furthermore support coordinated actions for achieving co-benefits and synergies among stakeholders (Gissi et al., submitted). Therefore, management needs to be boundary spanning both in terms of integrating different planning and management approaches (Winther et al., 2020; Dunstan et al., 2021), as well as at the science-policy interface (Posner et al., 2020).

Science plays an important role in guiding policy toward more sustainable pathways (Ramesh et al., 2015). However, the translation of scientific findings into policy and therefore action remains an outstanding issue, which has been identified as a major barrier to sustainable management of marine resources (Game et al., 2015; Dale et al., 2019). The need for "actionable knowledge" has been highlighted within environmental sustainability science (Caniglia et al., 2020; Mach et al., 2020; Wong-Parodi et al., 2020), which draws on the importance of increasing the uptake of scientific evidence through knowledge co-production with society (e.g., Norström et al., 2020; Folke et al., 2021). Clear communication between scientists and policy-makers facilitating a two-way knowledge exchange is imperative to improving mutual understanding and producing policy-relevant ocean science (Cvitanovic et al., 2015; Game et al., 2015; Drakou et al., 2017). This requires the integration of multiple disciplines as well as all relevant stakeholders within SES (Röckmann et al., 2015; Domínguez-Tejo et al., 2016; Delacámara et al., 2020; Pendleton et al., 2020). Hence, interand transdisciplinary approaches (see Box 2 for definitions) have become key at the interface between science and the implementation of coastal and ocean policy. Given an often diffuse boundary between these two approaches (Stock and Burton, 2011), we will further refer to them as "integrated" research approaches.

Despite a profound understanding of the impacts of environmental change on the ocean and an extensive body of literature on related ecological and societal challenges, "ocean action" has been lagging behind. Against this backdrop, the UN called out the Decade of Ocean Science for Sustainable Development (2021-2030), further referred to as "Decade of Ocean Science." It puts high emphasize on closing the so-called "research-implementation gap" (see Knight et al., 2008) by producing actionable knowledge that is efficiently communicated between science, policy, and society. Given still existing challenges to the integrated management of coastal and ocean resources in face of accelerating economic activities and environmental change, therefore, suggest that research needs to respond to these issues.

In light of the Decade of Ocean Science, this paper aims at providing key considerations for research approaches that tackle the outlined challenges in managing the ocean space. From a survey and review targeted at projects and initiatives that apply integrated approaches, we draw examples of challenges and goodpractices. Based on this, we propose three key considerations for integrated research that is aimed at the efficient communication between science, policy, and society in support of sustainable and integrated ocean management ${ }^{1}$. With this contribution, we emphasize the need for more integrated research projects within the Decade of Ocean Science.

"There is a compelling need for new trajectories of coastal research that transcend disciplinary boundaries and the barriers between science, policy, and practice in order to facilitate transformative changes necessary to transition toward safer and more resilient and sustainable pathways" (Ramesh et al., 2015).

\section{MATERIALS AND METHODS}

Given the inherent complexity of coastal and oceanic SES, this study aims to complement current knowledge from scientific literature investigating how to bridge the researchimplementation gap across epistemological, geographical, and institutional boundaries. We therefore draw on project-based and hands-on experiences of integrated projects and initiatives. Thereby, we want to shed light to the challenges and success stories of projects ranging from pure science, over citizen-science to management applications and provide an in-depth assessment of structural challenges, which are unlikely to be found in scientific publications or public material.

Projects and initiatives from the field of marine science and conservation were selected comprising a continuum from applied research to management and outreach. For a project to be included, it had to involve a multi, inter-, or transdisciplinary perspective. We aimed at covering a diversity of geographic origin and study foci, management areas, and institutional levels. Projects were expanded beyond academic research to account for practical experiences, which scientific projects could strongly benefit from, and identify shortcomings, which may highlight potential to close the research-implementation gap. We applied a qualitative approach, which can be used to establish an in-depth understanding of the perceptions of different participants, or in this case researchers and practitioners, and for identifying key principles of best practices (Blythe and Cvitanovic, 2020). Project selection was limited to the authors' knowledge and extended networks and therefore did not follow a systematic project review. Therefore, the results must be regarded as spot lights of extant projects rather than a representative project selection, which does not warrant inferences about general trends.

For each of the projects or initiatives included in the analysis, the following information was collated from publicly available resources: aims, time period, environmental or societal pressures addressed, academic disciplines involved, geographical focus, scientific method(s) applied, means and tools of communication, non-academic stakeholders consulted or involved, geographical location of conducted research, political institution(s) addressed, published papers (if available), funding type, and achievements.

\footnotetext{
${ }^{1}$ While Integrated Ocean Management refers to a specific management approach, we will further refer to integrated ocean management (with small letters) as we refer to it as a concept that needs to be addressed by science within the Decade of Ocean Science.
} 
BOX 2 |Definitions of multi-, inter-, and transdisciplinarity.

Language has often been mentioned as one of many barriers to integrated research (Bracken and Oughton, 2006; Donaldson et al., 2010) and terminology is often not used consistently or used interchangeably in this field. However, there are subtle, but significant differences between the terms "multi-," "inter-," and "transdisciplinarity," three main forms of integrated research. There is no common definition of these concepts, but based on reviewed literature in a sustainability context (Stock and Burton, 2011), they can be conceptualized as follows:

Multidisciplinarity - Presents the least integrative, but most attainable form of integrated research.

In multidisciplinary research, an object of study is approached from two or more unconnected disciplinary viewpoints, in succession and in isolation without any real interaction between them (Darbellay, 2015). Researchers aim to share knowledge and compare results from the studies, but there is no attempt to cross boundaries or generate new integrative knowledge.

What divides multidisciplinarity from the other concepts is the lack of iterative research, a failure to cross-disciplinary boundaries, the lack of integration in the research process, and a failure to engage non-academic stakeholders as participants in the research. In addition, multidisciplinarity may sometimes focus on the theme under investigation - rather than being problem-oriented and may or may not involve a coordinated program of research.

Interdisciplinarity - Can be regarded as a step up from multidisciplinarity, based on the level of integration and cooperation.

Interdisciplinarity goes beyond simply juxtaposing different disciplinary viewpoints, but rather bridges these viewpoints by enabling the examination of existing accumulated knowledge from the perspective of a neighboring discipline. It involves a collaborative and integrative approach by disciplines to a common object of study, in the joint production of knowledge (Darbellay, 2015). Respective studies commonly focus on addressing specific real-world problems.

Transdisciplinarity - Highest form of integrated project, and probably the most desirable and yet the one most difficult to obtain.

Transdisciplinary work aims to synthesize new disciplines (reconfiguring disciplinary divisions within a systemic, global, and integrated perspective) and theory (generating knowledge that transcends disciplinary boundaries) (Darbellay, 2015). It further emphasizes holism in its approach to problem solving by involving scientists and non-academic stakeholders. Adopting pluralist methodologies combines interdisciplinarity with participatory approaches to address complex problems.

As according to Stock and Burton (2011), the boundaries between inter- and transdisciplinary projects are often diffuse, and rather depend on subjective judgment about the level of holism applied, than on the presence of clear boundary indicators (Stock and Burton, 2011), we will further refer to both concepts as "integrated" research approaches.

Where applicable, good-practices, challenges, and suggestions were collated from gray literature including published articles, interviews, talks, and project websites.

To obtain more personal and in-depth insights, an online questionnaire (Supplementary Appendix 1) was designed and distributed to all projects via email. The survey followed the principle of prior informed consent, with the participants having been informed about the purpose of the survey and the inclusion of their information in a publication. Project names were provided on a voluntary basis. A list of the projects and initiatives included in this study can be found in Supplementary Appendix 2. Extracted information from the projects and questionnaire responses was analyzed to identify challenges and good-practices (section "Challenges and Good-Practices of Integrated Research Projects") and key considerations for an integrated research approach in support of integrated ocean management (section Key Considerations for an Integrated Research Approach). In total, information from 26 projects were collated and analyzed, of which 13 provided further information by responding to the survey.

From the 13 surveyed projects we collected further project details (see section "Project Details") regarding: the ocean basin(s) they cover; maritime zones covered; operational level of the project/initiative; academic disciplines involved; type of non-academic stakeholders involved; application of integrated approaches (classified by Stock and Burton, 2011); and funding type. The classification of integrated approaches into multi-, inter-, and transdisciplinary after Stock and Burton (2011) is thereby characterized by: problem solving focus; involvement of multiple disciplines; knowledge sharing between disciplines; involvement of non-academic stakeholders; synthesis of new disciplines and knowledge; iterative research process between disciplines; application of approaches that cross epistemological boundaries; and involvement of implementing results as part of the process.

\section{RESULTS}

The following section presents an overview of the projects and initiative that took part in the survey. The results are meant to be indicative, but, given the low response rate $(n=13)$, do not provide a comprehensive overview of existing global research projects and ocean initiatives. We therefore concentrate on a descriptive presentation of the results. In Table 1, we highlight the qualitative outputs from the survey and further information of all analyzed projects $(n=26)$ collected from publicly available resources. Respective findings including recommendations from survey respondents are presented and discussed in the context of recent literature in Section "Discussion," providing a more comprehensive picture of challenges and good-practices for integrated research projects.

The survey projects and initiatives cover all ocean basins except the Arctic Ocean and include all maritime zones from Internal Waters toward the High Seas. While $70 \%$ of all projects covered waters of the Territorial Seas and Exclusive Economic Zone, many projects also cover ABNJ. Specifically, 54\% of projects focus on the High Seas, $46 \%$ on the Continental Shelf, and $31 \%$ on "The Area" (seabed/ocean floor) (see Figure 1). Thereby, more than half of the projects (54\%) operate at the international level, while 15 and $31 \%$ operate at national and local to regional level, respectively. Funding was mainly provided by governmental or intergovernmental institutions (69 and $49 \%$, respectively), while also private sector, non-governmental 
TABLE 1 | Challenges and good-practices mentioned by surveyed projects and initiatives.

\begin{tabular}{ll}
\hline Challenges \\
\hline Addressing complexity & - Fragmentation of research efforts \\
$\bullet$ & Resource (i.e., time, personnel, and funding) \\
& and technical limitations \\
$\bullet$ & Hindrances in developing novel approaches in \\
& pilot projects \\
$\bullet$ & Lack of data and/or level of uncertainty makes \\
& managing cumulative stressors difficult \\
- & Diverse backgrounds impede establishment \\
engagement & and maintenance of trustful relationships \\
& among stakeholders \\
$\bullet$ & Elusive and complex stakeholder networks
\end{tabular}

Knowledge and data sharing

\begin{abstract}
Effective internal and external communication
\end{abstract}

Policy relevance

Funding

\section{Public involvement}

- Fragmentation of research efforts due to poor communication among partners

- Lack of accessible project-related data (internal and external use) during and beyond the project phase

- Knowledge sharing hinged by language barriers and different backgrounds (e.g., science, industry, local communities, etc.)

- Lack of a clear project or "brand" identity

- Lack of internal communication and trust among partners

- Difficulty in keeping the public engaged and informed

- Deliverables not stated or unclear

- Language barriers (both internal and external communication)

- Slow or limited implementation of knowledge into policy structures

- Unclear policy goals or gaps due to institutional complexity and lack of science-policy dialogues

- Projects relying on continued fundraising struggle to implement funding strategies at the design stage

- Difficulty to sustain funding throughout the project may limit its ability to carry out daily activities

- Inadequate funding schemes and structures for integrated research

- Lack of resources and experience in involving the public and complementing traditional research with, e.g., citizen science

- Language barriers (e.g., scientific jargon and indigenous communities)

\section{Good-practices}

$\checkmark$ Account for integrated approaches in the project structure to address complexity of SES

$\checkmark$ Provide support to include innovative methodologies

$\checkmark$ Reduce administrative barriers (e.g., further digitalization)

$\checkmark$ Project co-development with relevant stakeholders from the design stage on

$\checkmark$ Structured stakeholder dialogue to build mutual trust

$\checkmark$ Science is applicable and understood by stakeholders

$\checkmark$ Aims and objectives are well communicated to all stakeholders throughout the project

$\checkmark$ Structured international networks to facilitate collaboration across disciplines and fields

$\checkmark$ Facilitate mutual understanding and acknowledge property rights among stakeholders

$\checkmark$ Data sharing via a common (open access) platform

$\checkmark$ Ensure project output to be finable, accessible, interoperable, and reusable (FAIR principles)

$\checkmark$ Shared training and capacity building

$\checkmark$ Distinctive "brand" identity to ensure internal cohesion and facilitate outreach activities

$\checkmark$ Shared communication training

$\checkmark$ Clear, consistent, and up-to-date information for the public via a variety of media platforms

$\checkmark$ Clear internal communication of project aims and deliverables (bi-directional communication)

$\checkmark$ Use simple and inclusive language

$\checkmark$ Clearly address a legislative gap and policy from the design stage

$\checkmark$ Project co-development with relative legislative bodies (such as Regional Councils)

$\checkmark$ Scientific output translated and targeted to be easily understood by policy-makers

$\checkmark$ Ensure consistent, long-term funding through adequate funding strategy, which may be based on a variety of sources

$\checkmark$ Provide adequate reporting to and maintain a positive relationship with funders

$\checkmark$ Advocate for funding schemes and structures which facilitate integrated research (e.g., longevity, support innovations, interdisciplinary review and project architecture, outreach deliverables, etc.)

$\checkmark$ Account for public involvement in project design with adequate resources

$\checkmark$ Ensure active outreach and participatory approaches throughout the project

$\checkmark$ Involvement of youth and local community organizations

$\checkmark$ Use of inclusive language and actions

The subtopics are based on re-occurring, often interrelated subjects highlighted by the projects or initiatives in either published information or the survey.

institutions, and donations were mentioned as a source. One of the projects was not funded at all, but was carried out on a voluntary basis.
All projects and initiatives consulted or involved nonacademic stakeholders. The stakeholders involved covered representatives from (ordered from most mentioned to least 
mentioned): industry/business (85\%); governmental institutions (77\%); local communities (77\%); non-governmental institutions (69\%); educators (69\%); private foundations (62\%); media (54\%); culture and arts (46\%); and public health, tourism, youth groups, and indigenous communities ( $8 \%$ each).

Projects varied in the number and constellation of academic disciplines they combine, and in the degree of integration, depending on their purpose and aim. While natural sciences such as Ecology and Oceanography were predominantly applied by 93 and 69\%, respectively, social sciences including Economics, Political Sciences, and Sociology were applied by $39-46 \%$. A chord diagram visualizing the combinations of academic disciplines involved within investigated projects and initiatives is depicted in Figure 2. While some projects drew upon the expertise of up to nine disciplines, others simply combined two disciplines to develop novel ideas driving innovation. On the one hand, the Horizon 2020 project SOPHIE brought together marine and environmental scientists with medical and social scientists, public health, and other experts to tackle complex issues of SES in one joint forum. On the other hand, the Ecostructure project combines the two disciplines of ecology and engineering to find commercial solutions to enhance biodiversity along human-made coastal infrastructures such as marinas, by creating innovative constructions enhancing the structural complexity of facades.

The level of integration between different disciplines in the projects and initiatives, as characterized by Stock and Burton (2011), was mainly driven by the involvement of both multiple disciplines and non-academic stakeholders (100\% each), knowledge sharing between disciplines (85\%), and problem solving focus (62\%). Synthesis of new disciplines and knowledge, iterative research process between disciplines, application of approaches that cross epistemological boundaries, and involvement of implementing results as part of the process were mentioned by almost half of the projects (46\%). While all of the projects apply an integrated approach, more specifically, 46\% of the surveyed projects include transdisciplinary specific aspects.

Projects and initiatives were asked to provide information on their achievements, challenges, and good-practices. Table 1 provides an overview of the challenges and good-practices in conducting integrated research. The sections are based on reoccurring, often interrelated issues highlighted by the 26 projects and initiatives in either publicly available resources or the survey responses. In order to provide more context to the results presented in Table 1, they will be discussed in light of other literature in Section "Challenges and Good-Practices of Integrated Research Projects."

\section{DISCUSSION}

Given an increasing number of research projects around the world attempting to cross-disciplinary and epistemological boundaries, we here want to shed light on how to bridge the research-implementation gap across such boundaries. By including the challenges and good-practices from ongoing integrated projects, lessons can be learned and applied to new research projects aiming to cross this gap. In the following sections we will i) discuss the results from the survey, ii) identify key considerations for an integrated research approach in support

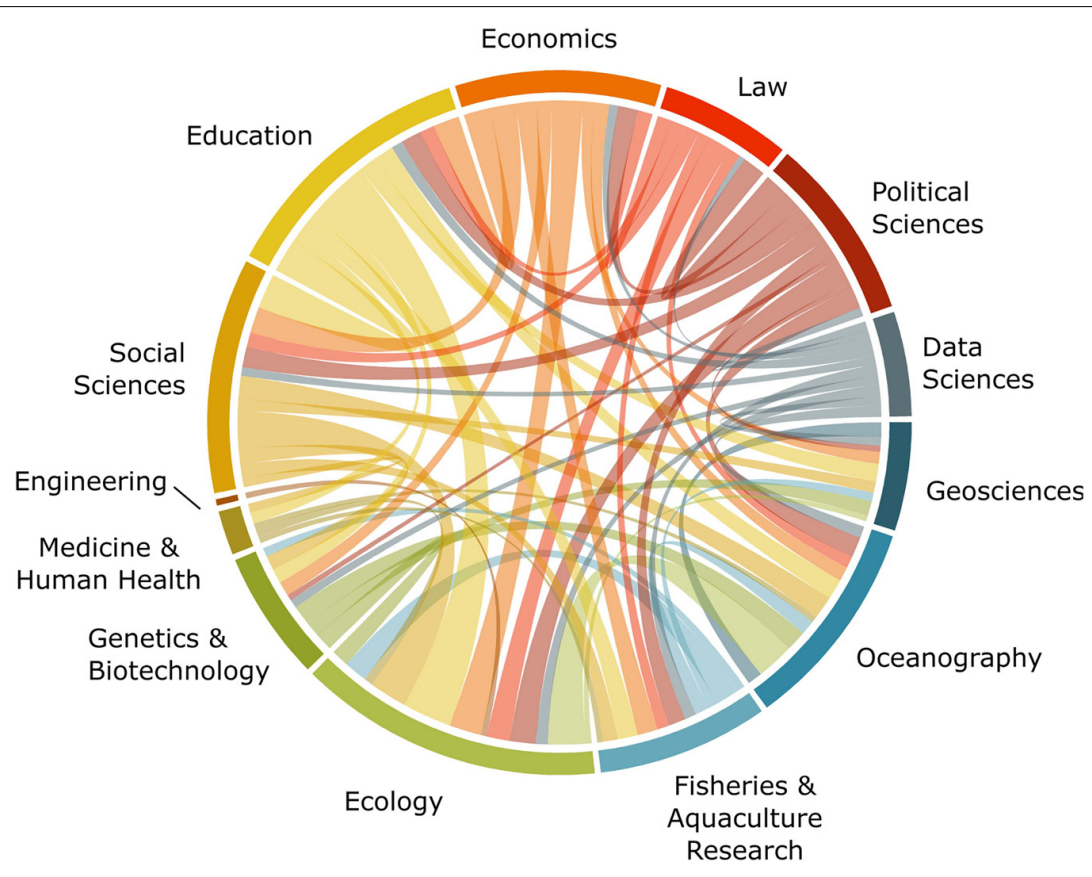

FIGURE 2 | Chord diagram visualizing the combinations of disciplines involved within investigated projects and initiatives. The thickness of the connections relates to the number of discipline combinations stated explicitly in the questionnaire. 
of integrated ocean management, and iii) provide an outlook for addressing the research-implementation gap in the "Decade of Ocean Science".

\section{Challenges and Good-Practices of Integrated Research Projects Addressing Complexity}

Most of the challenges faced by coastal and ocean ecosystems can be attributed to the complexity of SES and their inherent interrelationships between different system components (social, economic, and ecological), which are interlinked across scales (Chakraborty et al., 2020; Weise et al., 2020; Haas et al., 2021). Integrated research projects address this complexity from different perspectives by integrating knowledge from different disciplines, therefore providing a more comprehensive approach to coastal and ocean research and conservation. Yet, among the featured projects, the integration of multiple disciplines seemed to present a major challenge when addressing interconnected SES. In line with Blythe and Cvitanovic (2020), particularly the complexity of socio-political interactions has been mentioned to constitute a major obstacle by survey respondents. While different combinations of academic disciplines can create room for knowledge production, sharing and cross-disciplinary innovation (Markus et al., 2018), including multiple perspectives in a project, may lead to a fragmentation of research efforts instead of providing a more holistic view (Sievanen et al., 2012). There are many organizational obstacles in streamlining disciplines and methodologies in one project against the backdrop of time and funding limitations (Bos et al., 2015). This is particularly true for smaller initiatives, which as pilot projects are often limited in available capacities and knowhow, especially when developing or applying novel approaches. Further, a lack of comprehensive knowledge of the physical environment and technological limitations may diminish the ability to investigate and sustainably manage these systems. This is especially pronounced when it comes to deep-sea ecosystems, as in the Atlas project, where in-depth research and monitoring of deep-sea ecosystems are combined with technological innovation, outreach activities, and directed policy action. To better understand the complexity of marine ecosystems, cumulative stressors and associated risks and uncertainties need to be accounted for (Davies et al., 2018). Addressing these aspects through a cooperation with scientists, local communities, environmental groups, councils, and the central government, the Sustainable Seas National Science Challenge acknowledges the inherent complexity of marine management. To address it, this and other initiatives highlight the importance of a holistic EbM approach, which requires effective project co-design across all disciplines and stakeholders.

\section{Stakeholder Engagement}

To facilitate integrated research projects, which involve very distant disciplines and rely on collaborations stretching beyond academia, effective stakeholder engagement is fundamental (Lundquist and Granek, 2005; Ison et al., 2021). Multistakeholder processes ensure constant dialogue and thus longterm and equitable cooperation among those involved in the process. But following the questionnaire results, the involvement of stakeholders seems not to come without challenges. Building mutual understanding and trust among the stakeholders and with the project leaders requires time and an effective internal communication strategy which is bidirectional (encourages feedback) and uses an inclusive language. Examined projects also support the finding that effective and inclusive co-design and co-development generates a sense of ownership and responsibility, which in turn increases the likelihood of successful implementation as well as it ensures longevity and sustainability of the project (Brouwer et al., 2016; Merten et al., 2016). This is particularly key in heterogeneous stakeholder groups, which combine a wide array of cultural and training backgrounds, such as projects liaising with stakeholders outside of academia, including indigenous communities or industry.

This is demonstrated by the Mami Wata Project, in which centers of expertise such as the International Ocean Institute (IOI) are working with countries along the African Atlantic coast to make human utilization compatible with conservation interests by using Marine Spatial Planning (Queffelec et al., 2021). Given their experiences, a participatory communication strategy from the very beginning of the project is essential to provide a space in which different opinions and knowledge are respected and integrated into the process. This allows local stakeholders to identify with and feel part of the project and ensures science relevance, uptake, and implementation. Another example of successful stakeholder engagement is the Lyme Bay Reserve, which has from day one considered fishermen an active part of the project, listening to their local knowledge and needs and supporting them throughout the establishment and the maintenance of the reserve. In order to keep the catch fresh, reduce the utilization of polluting single-use items, and at the same time support the catch of local fish, fishermen were given ice-making machines and reusable fish boxes. These actions made them an active and collaborative part of the project (Singer and Jones, 2021). Integrated research projects like the Sustainable Seas National Science Challenge and the Atlas Project further underline that cooperation beyond academia and across sectors as well as the co-development of the projects objectives among stakeholders is key and proved very effective for a more comprehensive assessment and monitoring of a coastal SES and deep-sea ecosystems in ABNJ.

\section{Knowledge and Data Sharing}

Integrated research efforts and collaborations across disciplinary boundaries rely on effective knowledge and data sharing. Despite the facilitated information sharing and cross-disciplinary networking due to online sharing platforms and open-access publications (Álvarez-Romero et al., 2018), some research networks and communities are still fragmented, and openly accessible data and repositories are only slowly becoming mandatory (Guidi et al., 2020). Databases are often incompatible due to different architectures, which promotes bias, duplication, and inaccuracy, which is why scientists increasingly call for ocean data products to be findable, accessible, interoperable, and reusable, following the FAIR principles (Tanhua et al., 2021). Ensuring interoperability proves particularly difficult when trying 
to establish partnerships which reach beyond academia to governance bodies or industry. Alongside scientific data sharing, local and traditional knowledge and good-practices from local stakeholder-driven projects have to be distributed as well, to facilitate successful implementation of projects on the ground (Mellado et al., 2014). Data and knowledge transfer needs to facilitate collaboration beyond the core stakeholder group and be designed as to ensure the project's longevity via platforms which are accessible to research communities and wider society in the long term, which in turn requires adequate funding schemes. Many among the considered projects mentioned knowledge sharing, and trust building as one key challenge to address in integrated projects, mentioning partners "all working together, but not sharing knowledge." Thus, promoting capacity building and shared training has come up among the questionnaire results as a possible solution to increase knowledge sharing in an equitable and complementary way, which will in turn facilitate cooperation among disciplines, as also found by Stojanovic et al. (2010).

Among the featured projects, the implementation of knowledge and open data sharing has proven an effective instrument to promote ocean sustainability in projects like Global Fishing Watch. Using satellite technology and machine learning, with the support of IT and digital partnerships (i.e., Google), it monitors commercial fishing allowing anyone to track fishing activity with near real-time tracking via a public map. With a platform making related data freely accessible, the project facilitates scientific research, enhances ocean literacy, and advocates for better fisheries policies in support of ocean protection and sustainable management, such as in the efforts to minimize illegal, unreported, and unregulated (IUU) fishing (Merten et al., 2016). The project in turns represents an innovative, interdisciplinary solution to share knowledge, data, and information at the service of marine conservation.

\section{Effective Internal and External Communication}

To facilitate stakeholder engagement and ensure long-term partnerships, effective communication is imperative. In line with previous findings (Cooke et al., 2017), our project-based analysis demonstrates that communication is among the chief reasons why projects tend to fail in achieving their objectives. Particularly, when asked about naming suitable approaches or actions toward bridging the gap between science, society, and policy for future ocean protection, most survey respondents mentioned the importance of internal project communication for trust building between partners. More disciplines often result in more entities, partners, and stakeholders involved, making relation building, trust, and communication not rarely complicated (Cvitanovic et al., 2020). Additionally, research institutes often rely on complex formalities that have been mentioned to often limit communication and inhibit a more fertile working environment. Maintaining an open and less formal working environment among project stakeholders might enhance relation building and trust, and in turn facilitate more integrated research. Online project management platforms, as well as digitalization and automation of administrative and formal decisions, could also prove useful in keeping a transparent and smooth internal communication and administration (Stevens et al., 2021).

Survey responses highlight that scientists are required to receive better education opportunities to develop appropriate communication skills to improve both internal and external communication, which previously has also been pointed out by other authors (Brownell et al., 2013; Bartel et al., 2019). An adaptive communication strategy seems to be required which can evolve with the project and ensures that aims, objectives, and respective changes are communicated effectively to all partners through all project stages. Creating an understanding for the importance of collaboration and fostering the establishment of a "bridge of communication" which explains individual objectives against the backdrop of a common vision to all partners, was mentioned as one of the key means by the Atlas Project to bridge the gap between stakeholders and generate a sense of ownership, which Blythe and Cvitanovic (2020) refer to as "cultivating a visible brand." Further, the role of "translating" or "boundary" organizations which integrate science communication experts in the project could be considered at the design stage to support communication at the science-policy interface (McDonald et al., 2018; Arnott et al., 2020).

In order to facilitate sharing of information across all stakeholders as well as the public, language barriers must be considered in internal and external communication (Bullock et al., 2019). Within research, disciplines use different terminologies and concepts, which allows for miscommunication between academic fields. Yet even stronger barriers exist as soon as projects involve non-academic partners such as local communities, as in case of the Mami Wata Project. To reach the wider public, external communication strategies can build on multiple communication channels besides scientific publications. Featured project distributed reports, policy briefs, or disseminated shareable infographics or short videos online. Innovative communication and visualization tools such as storytelling or gaming are also critically important when it comes to disseminating project findings and targeting wider audiences (Green et al., 2018). For instance, the ResponSEAble project designed a novel ocean game to test Ocean Literacy, one of the elected pillars of the Decade of Ocean Science (Borja et al., 2020), among participants and ran a series of webinars, so-called "Ocean Dialogs” (Pantò, 2019). Keeping online platforms consistently updated, active, and easily accessible has been reported to contributing to the success of such projects. The more people are aware about our impact on the ocean and the ocean's impact on us, the more involved will the public and the more integrated will the solutions be for future ocean management.

\section{Policy Relevance}

If well-communicated, integrated research can provide valuable assets to bridge the gap between science and policy (Markus et al., 2018). However, many of the investigated projects find it difficult to make their findings accessible to and applicable for policy-makers. To ensure the uptake of scientific findings into decision-making, science needs to be policy-relevant and tailored to the policy cycle from the design stage (Game et al., 2015; Rose and Parsons, 2015). To this end, project 
design has to consider project outcomes that can be linked to currently debated policy issues or be framed in a way that they can contribute to political agenda setting (Parsons et al., 2015). The variety of governance bodies responsible different policy acts, including coastal management plans or international directives or agreements, can make it confusing for projects to identify relevant decision makers. Identifying such linkages therefore requires a thorough understanding of the existent governance frameworks prior to research design, and in some cases, it may be beneficial to include policy elicit experts in the design process. By conducting consecutive surveys on seabed biotopes in line with the European Environmental Agency EUNIS Habitat Type Classification (Wood et al., 2014) rather than focusing on single species, the marine citizen science project SEASEARCH for example has assisted the national government of the United Kingdom in the process of designating Marine Conservation Zones. In addition to a good understanding of extant governance framework, an effective communication strategy is key to allow for feedback mechanisms to avoid misunderstandings and ensure it to be fit for purpose. In terms of effective means of communicating project outputs to policymakers, many projects view the integration of infographics, policy briefs, or summaries for policy-makers as a strong tool.

\section{Funding}

Even with an effective communication and stakeholder-engaging strategy which ensures policy-relevance, the success of almost every integrated research project is dependent on the amount and conditions under which resources are available (Blythe and Cvitanovic, 2020). Funding is widely considered to be the most critical and limiting factor to a project success (Bos et al., 2015; Laufer and Jones, 2021). On the other hand, this high importance also poses a chance, as funding can constitute an important driver of change in the research landscape. Despite the observable trend to increasingly provide funds to inter- or even transdisciplinary projects and consider outreach and communication activities as part of the deliverables, the acquisition of funding for integrated projects, which cross disciplinary and geographical boundaries, often proves difficult.

In part, internal structures of funding agencies still seem to reflect traditional funding schemes, tailored toward single discipline projects. National funds can hamper international collaboration and envisaged project architecture (e.g., choice of leader, location, and reporting) is often not fit for purpose. Further, review and evaluation mechanisms of funding agencies are often not suited to assess integrated research projects adequately, requiring rather interdisciplinary performance metrics as well as adjusted evaluation hierarchies and reviewer expertise (Lyall et al., 2013; Blythe and Cvitanovic, 2020). In some cases, it might also be a lack of knowledge among researchers about the institutional capacities supporting interdisciplinary knowledge production (Blythe and Cvitanovic, 2020). Yet, in line with earlier findings (Bos et al., 2015), many projects among those featured, stated that the continuous lack of adequate funding compromised the quality and quantity of their work as funding opportunities are rare, and if available often inadequate in terms of size, duration, diversity of source, usage, and planning timings. One respondent reported that their funding capacity was too limited to accommodate all staff and volunteers interested in participating in the project. For pilot projects, which utilize innovative but non-established approaches and methodologies, often involving integrated approaches, it is especially difficult to acquire funding. In addition, there is a particular lack of longterm funding, despite its high relevance for long-term monitoring (Blythe and Cvitanovic, 2020). Such funding not only sustains the initiation and execution of the project in question but also ensures its adaptability in the face of unforeseen problems and changes (Kalpazidou Schmidt, 2020). Yet, many of the European grant schemes supporting some of the featured projects and initiatives, as well as other local, national, and international financial support are often restricted in time (1-5 years), which makes it difficult for projects to develop and establish. Further, projects often end abruptly with the end of the funding period and generated knowledge, material, or data are not transferred to follow-up projects or accessible long-term repositories (Blasiak et al., 2019). The most long-lasting and successful projects among those considered had a variety of trusted sponsors and local, national, or international political support, emphasizing the need for consistent, and well-structured long-term funding from a diverse array of sources.

\section{Public Involvement}

Not only policy responsiveness from policy-makers, but also responsiveness from society such as through the inclusion of a wider public has been shown to significantly increase the success of environmental projects (Grodzińska-Jurczak and Cent, 2011; Burgos-Ayala et al., 2020). And indeed, the involvement of the broader public in research has gained traction through the last years. The latest call by the European Commission lists "empowering citizens" as one of the thematic areas within the Horizon 2020 European Green Deal Call (European Commission, 2020). While respondents of our survey see the need for more outreach, they see both chances and challenges in participatory approaches. Citizen Science projects can offer opportunities to gather large quantities of data on large spatial and temporal scales (Earp and Liconti, 2019); however, survey respondents have pointed out the difficulty of applying citizen science to traditional research procedures such as benthic surveys, due to the need for training and standardized methodology. Furthermore, the engagement process is challenging. Public engagement is not only fundamental to keep up the motivation of participants, but also requires a large amount of time and capacity to feedback regular updates and build relationship and excitement. Projects such as Fjord Phyto, which engages with more than 3000 travelers to engage in polar research, have been great examples. Even though such citizen projects are difficult to coordinate, international projects such as the Ocean Plastics Lab have succeeded in engaging with local communities by increasing their impact at the local scale and providing accessible outputs (open exhibitions, flyers, and public talks). For new research approaches to be sustainable and long-term, especially in coastal governance, public support and compliance are essential and are needed as a pivotal work-package, when designing an integrated project 
(McKinley and Fletcher, 2011). This said, the involvement of public in marine research and conservation remains one of the most challenging, yet most effective and rewarding aspects of integrated projects and initiatives.

\section{Key Considerations for an Integrated Research Approach}

Integrated research projects in coastal and ocean science lie at a crossroad of good-practices and unresolved challenges, as described above. Some of the challenges that arose from the selected projects relate to the project design. If well designed, the holistic perspective that these projects provide could prove fundamental in addressing targets set out in intergovernmental agreements and particularly within the Decade of Ocean Science. By integrating some key principles in the planning cycle, the success of respective research projects or initiatives, and thereby their conservation outputs, could be promoted. Building on the results from Section "Challenges and Good-Practices of Integrated Research Projects" and further information provided by surveyed projects, we propose three key considerations for an integrated research approach (see Figure 3), which aims at bridging the research-implementation gap for better science-informed decision-making in support of integrated ocean management.

1. Target setting, resource management, and adaptive planning

At the core of a successful integrated research project, a clear target, sufficient resources and adaptive planning are essential. Clearly defined targets are particularly necessary for environmental policymaking in order to translate scientific findings into political objectives and to guide policy decisions toward implementation (Neumann et al., 2017; Dreujou et al., 2020). Our analysis suggests that the objectives of an integrated project can address different issues, such as a specific environmental policy gap, or societal problems (see point 3). For addressing the complexity of coastal and ocean SES, innovative approaches may be indispensable, but the implementation is often challenging. In order to achieve ambitious goals different resources, e.g., financial, human, temporal, and institutional, are required. Even though the availability of financial resources is beyond the influence of individual researchers and project managers, a clear fundraising strategy can support consistent and long-term funding of the project. Further, as clearly highlighted in this paper, crossing academic boundaries and synthesising new knowledge through the involvement of experts from different scientific and non-scientific disciplines will increase the capacities of integrated projects to achieve ambitious environmental sustainability goals. An improved understanding about institutional capacities that support interdisciplinary knowledge production may therefore prove beneficial (Blythe and Cvitanovic, 2020). Due to the inherent complexity of the marine environment which is reflected in the structure of integrated projects themselves, it is presupposed that project actions are planned reflectively requiring adaptive and strategic management. This includes setting appropriate timeframes at the planning stage, which leave room for unforeseen changes and encompass strategies how project outputs can add value in the long-term, beyond the active project phase (e.g., through consistent monitoring and evaluation).

2. Knowledge production and responsiveness toward policy and society

To facilitate collaboration within science, knowledge exchange and transfer should be facilitated and follow the FAIR principles. In this context, researcher networks crossing geographic, disciplinary, and institutional boundaries are valuable. However, knowledge production in integrated research projects is highly dependent on collaborations beyond academia, throughout the project. A clear target in form of a common vision among all stakeholders is pivotal for integrated research to be responsive to political and societal needs (IPCC, 2019). Including local and traditional knowledge, capacity building, and improving ocean literacy at the local level are acknowledged to foster ownership among stakeholders and to sustain their active involvement in management processes. This will ultimately support achieving a desirable and possibly more sustainable state of the SES.

3. Co-design, co-development, cooperation, and effective communication

True political and societal responsiveness requires a knowledge exchange that can only be achieved by a co-designed, codeveloped, and cooperative process. This means that integrated research projects need to engage with stakeholders from the design stage on, to build mutual trust and understanding and ensure collaborative implementation. Feedback from and exchange among policy and society will also facilitate to create novel approaches together with the stakeholders. This relies on effective communication, which allows a bi-directional, equitable exchange by making use of simple and inclusive language. To this end, the means of communication have to be tailored to the audience and should include feedbacks directed to both the public and policy-makers, which may involve participatory approaches such as citizen science and public discussions and provide output that is accessible via multiple platforms.

\section{Outlook: Addressing the Research-Implementation Gap in the "Decade of Ocean Science"}

Given the increasing awareness of policy and society toward the need for effective and integrated ocean management, the momentum for "ocean action" needs to be taken up in the Decade of Ocean Science. This requires not only action at the scientific level toward improved science-based and policytargeted research, but also a transformation at the system's level to achieve effective implementation. Strong political will and social commitment are often required in high-level decision-making processes. Still, researchers can contribute to more effective science-based decision-making through policy-targeted research projects. By following integrated research agendas, outputs are capable of addressing complex SES more holistically and thus are better tailored to the realities of society and policy-makers, 


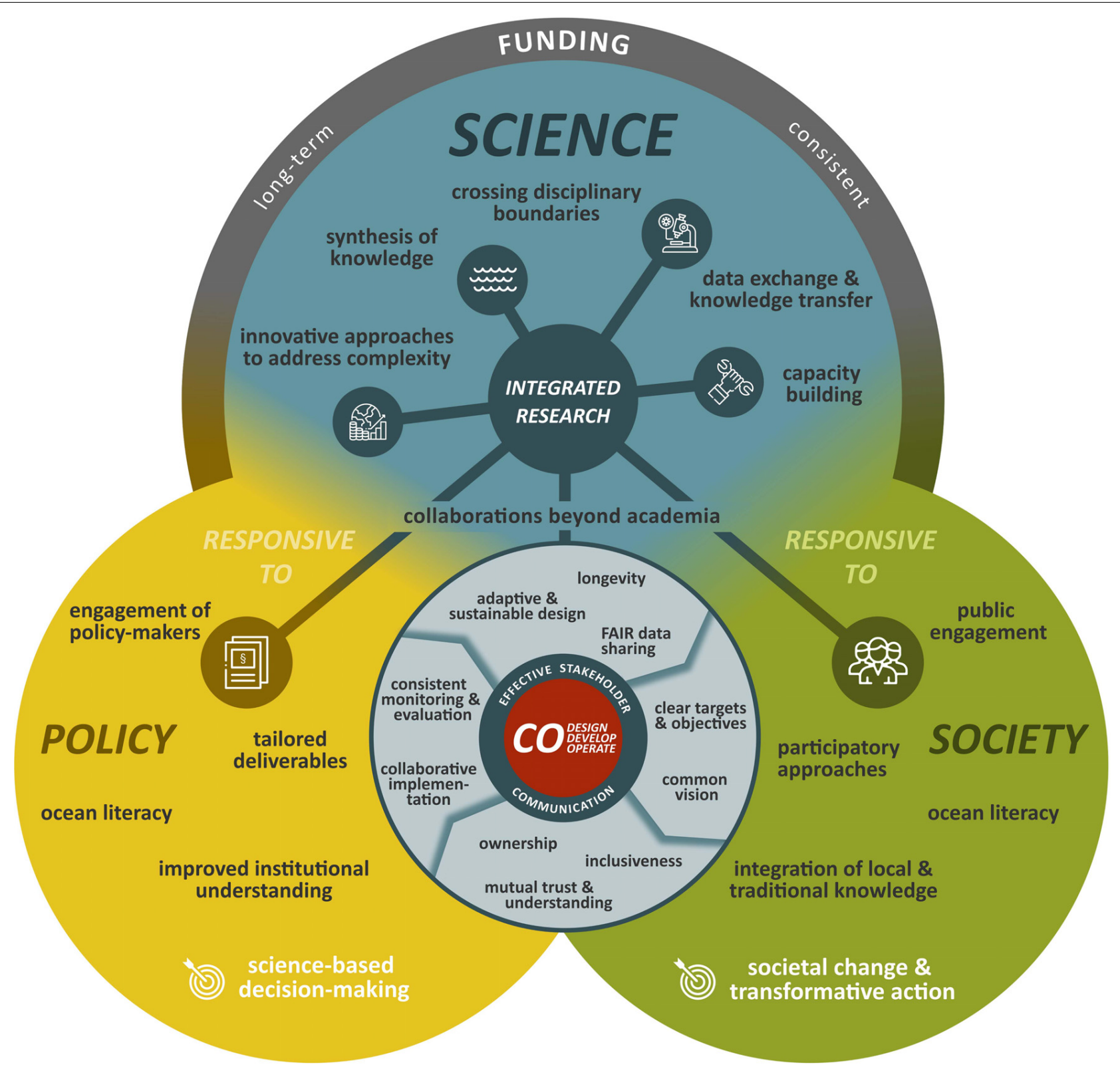

FIGURE 3 | Schematic overview of key considerations for an integrated research design, based on a co-developed approach with policy and society to effectively bridge the research-implementation gap.

increasing their effective uptake. Thereby, science can provide a starting point for a structured dialogue with society and politics on pathways toward integrated ocean management for a more sustainable and resilient ocean. Such discourses will in turn facilitate joint action with the potential to trigger the transformative changes required in light of trade-offs between increasing economic activities and global sustainability goals (Ramesh et al., 2015; Norström et al., 2020; Rudolph et al., 2020). At the same time, structural changes of the academic landscape and respective funding bodies are required to support integrated approaches. Capacity building, for example, may also include the training of early career researchers (ECR) in applying an integrated research approach (Brasier et al., 2020). Given the often purely disciplinary and academic education focus, it is particularly challenging for ECR to integrate a variety of disciplines and concepts. Discussion among researchers from different professional levels is needed on what challenges and opportunities are entailed in applying integrated approaches and what future professional pathways in coastal and ocean science exist for ECR.

The key considerations laid out in this paper (Figure 3) may support researchers at all career stages to design integrated research approaches within the Decade of Ocean Science. Through strong and inclusive collaborations which reach beyond 
disciplines and epistemological boundaries, researchers have the opportunity to actively engage in decision making on all levels. Thereby, they can facilitate effective implementation of sciencebased knowledge and thus contribute to initiating transformative change toward integrated management for a healthy, productive, and (climate) resilient ocean integrated ocean management.

\section{DATA AVAILABILITY STATEMENT}

The original contributions presented in the study are included in the article/Supplementary Material, further inquiries can be directed to the corresponding author/s.

\section{ETHICS STATEMENT}

Ethical review and approval was not required for this study with human participants, in accordance with the local legislation and institutional requirements. Informed consent to participate in this study was provided by the participants.

\section{AUTHOR CONTRIBUTIONS}

LR, CK, AL, and NP conceived the original idea of the manuscript, designed the suvey, and conceptualized Figure 3. LR led the project. AL, NP, and CK reviewed and analyzed the projects and initiatives. LR wrote the introduction, results, and key considerations. NP and CK wrote the methods. AL and CK

\section{REFERENCES}

Álvarez-Romero, J. G., Mills, M., Adams, V. M., Gurney, G. G., Pressey, R. L., Weeks, R., et al. (2018). Research advances and gaps in marine planning: towards a global database in systematic conservation planning. Biol. Conserv. 227, 369-382. doi: 10.1016/j.biocon.2018.06.027

Ardron, J. A., Rayfuse, R., Gjerde, K., and Warner, R. (2014). The sustainable use and conservation of biodiversity in ABNJ: What can be achieved using existing international agreements? Mar. Policy 49, 98-108. doi: 10.1016/j.marpol.2014. 02.011

Arnott, J. C., Mach, K. J., and Wong-Parodi, G. (2020). Editorial overview: The science of actionable knowledge. Curr. Opin. Environ. Sustain. 42, A1-A5. doi: 10.1016/j.cosust.2020.03.007

Bartel, B., Agopian, M., and Bohon, W. (2019). The unexpected benefits of science communication training. Eos 100:023. doi: 10.1029/2019eo129023

Blasiak, R., Wabnitz, C. C. C., Daw, T., Berger, M., Blandon, A., Carneiro, G., et al. (2019). Towards greater transparency and coherence in funding for sustainable marine fisheries and healthy oceans. Mar. Policy 107:103508. doi: 10.1016/j. marpol.2019.04.012

Blythe, J., and Cvitanovic, C. (2020). Five organizational features that enable successful interdisciplinary marine research. Front. Mar. Sci. 7:981. doi: 10. 3389/fmars.2020.539111

Borja, A., Santoro, F., Scowcroft, G., Fletcher, S., and Strosser, P. (2020). Editorial: connecting people to their oceans: issues and options for effective ocean literacy. Front. Mar. Sci. 6:837. doi: 10.3389/fmars.2019.00837

Bos, M., Pressey, R. L., and Stoeckl, N. (2015). Marine conservation finance: The need for and scope of an emerging field. Ocean Coast. Manag. 114, 116-128. doi: 10.1016/j.ocecoaman.2015.06.021

Boyes, S. J., and Elliott, M. (2014). Marine legislation - The ultimate "horrendogram": International law, European directives \& national wrote the challenges and good-practices. CK wrote Boxes 1, 2 and created all the figures. LR and CK wrote the outlook and edited the final version. All authors approved of the final version of the manuscript.

\section{ACKNOWLEDGMENTS}

We sincerely thank everyone who participated in the online questionnaire and shared their insights from their integrated research projects and initiatives. Furthermore, we thank Louis Celliers and Timothy Thomson for their valuable comments on an earlier version of the manuscript. Figures 1, $\mathbf{3}$ were produced using Inkscape (http://www.inkscape.org/) using resources from flaticon (www.flaticon.com). Figure $\mathbf{2}$ was produced using the $\mathrm{R}$ package circlize ( $\mathrm{Gu}$ et al., 2014). LR acknowledges funding from the Helmholtz-Zentrum Hereon project I2B CoastalClimateServices@GERICS. This work contributes to Future Earth Coasts, a Global Research Project of Future Earth.

\section{SUPPLEMENTARY MATERIAL}

The Supplementary Material for this article can be found online at: https://www.frontiersin.org/articles/10.3389/fmars. 2021.693373/full\#supplementary-material

Supplementary Appendix 1 | Online Questionnaire.

Supplementary Appendix 2 | List of projects and initiatives considered in the analysis.

implementation. Mar. Pollut. Bull. 86, 39-47. doi: 10.1016/j.marpolbul. 2014.06.055

Bracken, L. J., and Oughton, E. A. (2006). What do you mean?" The importance of language in developing interdisciplinary research. Trans. Inst. Br. Geogr. 31, 371-382. doi: 10.1111/j.1475-5661.2006.00218.x

Brasier, M. J., McCormack, S., Bax, N., Caccavo, J. A., Cavan, E., Ericson, J. A., et al. (2020). Overcoming the obstacles faced by early career researchers in marine science: lessons from the marine ecosystem assessment for the Southern Ocean. Front. Mar. Sci. 7:692. doi: 10.3389/fmars.2020.00692

Brouwer, H., Woodhill, J., Hemmati, M., Verhoosel, K., and van Vugt, S. (2016). The MSP Guide: How to Design and Facilitate Multi-Stakeholder Partnerships. Wageningen: Practical Action Publishing.

Brown, S., Nicholls, R. J., Hanson, S., Brundrit, G., Dearing, J. A., Dickson, M. E., et al. (2014). Shifting perspectives on coastal impacts and adaptation. Nat. Clim. Chang. 4, 752-755. doi: 10.1038/nclimate2344

Brownell, S. E., Price, J. V., and Steinman, L. (2013). Science communication to the general public: Why we need to teach undergraduate and graduate students this skill as part of their formal scientific training. J. Undergrad. Neurosci. Educ. 12, 6-10.

Bullock, O. M., Colón Amill, D., Shulman, H. C., and Dixon, G. N. (2019). Jargon as a barrier to effective science communication: Evidence from metacognition. Public Underst. Sci. 28, 845-853. doi: 10.1177/0963662519865687

Burgos-Ayala, A., Jiménez-Aceituno, A., and Rozas-Vásquez, D. (2020). Integrating ecosystem services in nature conservation for Colombia. Environ. Manage. 66, 149-161. doi: 10.1007/s00267-020-01301-9

Campbell, L. M., Gray, N. J., Fairbanks, L., Silver, J. J., Gruby, R. L., Dubik, B. A., et al. (2016). Global oceans governance: new and emerging issues. Annu. Rev. Environ. Resour. 41, 517-543. doi: 10.1146/annurev-environ-102014-021121

Caniglia, G., Luederitz, C., von Wirth, T., Fazey, I., Martín-López, B., Hondrila, K., et al. (2020). A pluralistic and integrated approach to action-oriented 
knowledge for sustainability. Nat. Sustain. 4, 93-100. doi: 10.1038/s41893-02000616-z

Celliers, L., Rosendo, S., Costa, M. M., Ojwang, L., Carmona, M., and Obura, D. (2020). A capital approach for assessing local coastal governance. Ocean Coast. Manag. 183:104996. doi: 10.1016/j.ocecoaman.2019.104996

Chakraborty, S., Gasparatos, A., and Blasiak, R. (2020). Multiple values for the management and sustainable use of coastal and marine ecosystem services. Ecosyst. Serv. 41:101047. doi: 10.1016/j.ecoser.2019.101047

Convention on Biological Diversity. (2010). COP 10 Decision X/2. Strategic Plan for Biodiversity 2011-2020. Available Online at: https://www.cbd.int/decision/cop/ ?id=12268 [Accessed April 6, 2020]

Cooke, S. J., Gallagher, A. J., Sopinka, N. M., Nguyen, V. M., Skubel, R. A., Hammerschlag, N., et al. (2017). Considerations for effective science communication. FACETS 2:55. doi: 10.1139/facets-2016-0055

Costanza, R., de Groot, R., Braat, L., Kubiszewski, I., Fioramonti, L., Sutton, P., et al. (2017). Twenty years of ecosystem services: How far have we come and how far do we still need to go? Ecosyst. Serv. 28, 1-16. doi: 10. 1016/j.ecoser.2017.09.008

Cumming, G. S., and Peterson, G. D. (2017). Unifying research on social-ecological resilience and collapse. Trends Ecol. Evol. 32, 695-713. doi: 10.1016/j.tree.2017. 06.014

Cvitanovic, C., Colvin, R. M., Reynolds, K. J., and Platow, M. J. (2020). Applying an organizational psychology model for developing shared goals in interdisciplinary research teams. One Earth 2, 75-83. doi: 10.1016/j.oneear. 2019.12.010

Cvitanovic, C., Hobday, A. J., van Kerkhoff, L., Wilson, S. K., Dobbs, K., and Marshall, N. A. (2015). Improving knowledge exchange among scientists and decision-makers to facilitate the adaptive governance of marine resources: A review of knowledge and research needs. Ocean Coast. Manag. 112, 25-35. doi: 10.1016/j.ocecoaman.2015.05.002

Dale, P., Sporne, I., Knight, J., Sheaves, M., Eslami-Andergoli, L., and Dwyer, P. (2019). A conceptual model to improve links between science, policy and practice in coastal management. Mar. Policy 103, 42-49. doi: 10.1016/j.marpol. 2019.02.029

Darbellay, F. (2015). Rethinking inter- and transdisciplinarity: Undisciplined knowledge and the emergence of a new thought style. Futures 65, 163-174. doi: 10.1016/j.futures.2014.10.009

Davies, K., Fisher, K., Foley, M., Greenaway, A., Hewitt, J., Le Heron, R., et al. (2018). Navigating collaborative networks and cumulative effects for Sustainable Seas. Environ. Sci. Policy 83, 22-32. doi: 10.1016/J.ENVSCI.2018. 01.013

de Alencar, N. M. P., Le Tissier, M., Paterson, S. K., and Newton, A. (2020). Circles of coastal sustainability: A framework for coastal management. Sustainability 12:4886. doi: 10.3390/su12124886

Delacámara, G., O’Higgins, T. G., Lago, M., and Langhans, S. (2020). “EcosystemBased Management: Moving from Concept to Practice," in Ecosystem-Based Management, Ecosystem Services and Aquatic Biodiversity. Cham: Springer International Publishing, 39-60.

Diz, D., Johnson, D., Riddell, M., Rees, S., Battle, J., Gjerde, K., et al. (2018). Mainstreaming marine biodiversity into the SDGs: The role of other effective area-based conservation measures (SDG 14.5). Mar. Policy 93, 251-261. doi: 10.1016/j.marpol.2017.08.019

Domínguez-Tejo, E., Metternicht, G., Johnston, E., and Hedge, L. (2016). Marine spatial planning advancing the ecosystem-based approach to coastal zone management: A review. Mar. Policy 72, 115-130. doi: 10.1016/j.marpol.2016. 06.023

Donaldson, A., Ward, N., and Bradley, S. (2010). Mess among disciplines: Interdisciplinarity in environmental research. Environ. Plan. A 42, 1521-1536. doi: $10.1068 / \mathrm{a} 42483$

Drakou, E. G., Kermagoret, C., Liquete, C., Ruiz-Frau, A., Burkhard, K., Lillebø, A. I., et al. (2017). Marine and coastal ecosystem services on the science-policypractice nexus: Challenges and opportunities from 11 European case studies. Int. J. Biodivers. Sci. Ecosyst. Serv. Manag. 13, 51-67. doi: 10.1080/21513732. 2017.1417330

Dreujou, E., Carrier-Belleau, C., Goldsmit, J., Fiorentino, D., Ben-Hamadou, R., Muelbert, J. H., et al. (2020). Holistic environmental approaches and aichi biodiversity targets: accomplishments and perspectives for marine ecosystems. PeerJ. 8:e8171. doi: 10.7717/peerj.8171
Dunn, D. C., Jablonicky, C., Crespo, G. O., McCauley, D. J., Kroodsma, D. A., Boerder, K., et al. (2018). Empowering high seas governance with satellite vessel tracking data. Fish Fish. 19, 729-739. doi: 10.1111/faf.12285

Dunstan, P. K., Celliers, L., Cummins, V., Elliott, M., Evans, K., Firth, A., et al. (2021). "Chapter 27: Development of management approaches," in The Second World Ocean Assessment. New York: United Nations, 441-465.

Earp, H. S., and Liconti, A. (2019). "Science for the Future: The Use of Citizen Science in Marine Research and Conservation," in YOUMARES 9 - The Oceans: Our Research, Our Future, ed. S. Jungblut (Cham: Springer International Publishing), 1-19. doi: 10.1007/978-3-030-20389-4_1

European Commission. (2008). Directive 2008/56/EC of the European Parliament and of the council establishing a framework for community action in the field of marine environmental policy (Marine Strategy Framework Directive). Off. J. Eur. Union, 164, 19-40.

European Commission. (2020). Title: Enabling citizens to act on climate change and environmental protection through education, citizen science, observation initiatives, and civic involvement. Available Online at: https://webgate.ec. europa.eu/fpfis/wikis/display/AtlasOfSeas/ [Accessed March 29, 2021].

European Environment Agency. (2020). The European environment - state and outlook 2020. Denmark: European Environment Agency.

Folke, C., Polasky, S., Rockström, J., Galaz, V., Westley, F., Lamont, M., et al. (2021). Our future in the Anthropocene biosphere. Ambio 50, 834-869. doi: 10.1007/s13280-021-01544-8

Frazão Santos, C., Agardy, T., Andrade, F., Calado, H., Crowder, L. B., Ehler, C. N., et al. (2020). Integrating climate change in ocean planning. Nat. Sustain. 3, 505-516. doi: 10.1038/s41893-020-0513-x

Gaebel, C., Baulcomb, C., Johnson, D. E., and Roberts, J. M. (2020). Recognising stakeholder conflict and encouraging consensus of 'Science-Based Management' approaches for marine Biodiversity Beyond National Jurisdiction (BBNJ). Front. Mar. Sci. 7:754. doi: 10.3389/fmars.2020.557546

Game, E. T., Schwartz, M. W., and Knight, A. T. (2015). Policy relevant conservation science. Conserv. Lett. 8, 309-311. doi: 10.1111/conl.12207

Gissi, E., Manea, E., Mazaris, A. D., Fraschetti, S., Almpanidou, V., Bevilacqua, S., et al. (2021). A review of the combined effects of climate change and other local human stressors on the marine environment. Sci. Total Environ. 755:142564. doi: 10.1016/j.scitotenv.2020.142564

Gjerde, K. M., Reeve, L. L. N., Harden-Davies, H., Ardron, J., Dolan, R., Durussel, C., et al. (2016). Protecting Earth's last conservation frontier: scientific, management and legal priorities for MPAs beyond national boundaries. Aquat. Conserv. Mar. Freshw. Ecosyst. 26, 45-60. doi: 10.1002/aqc.2646

Green, S. J., Grorud-Colvert, K., and Mannix, H. (2018). Uniting science and stories: Perspectives on the value of storytelling for communicating science. FACETS 3, 164-173. doi: 10.1139/facets-2016-0079

Grodzińska-Jurczak, M., and Cent, J. (2011). Can public participation increase nature conservation effectiveness? Innov. Eur. J. Soc. Sci. Res. 24, 371-378. doi: 10.1080/13511610.2011.592069

Gu, Z., Gu, L., Roland, E., Schlesner, M., and Brors, B. (2014). Circlize implements and enhances circular visualization in R. Bioinformatics 30, 2811-2812. doi: 10.1093/bioinformatics/btu393

Guidi, L., Fernàndez-Guerra, A., Bakker, D., Canchaya, C., Curry, E., Foglini, F., et al. (2020). "Big Data in Marine Science," in Future Science Brief 6 of the European Marine Board, eds B. Alexander, J. J. Heymans, A. Munpiz Piniella, P. Kellett, and J. Coopman (Ostend, Belgium: ZENODO).

Haas, B., Mackay, M., Novaglio, C., Fullbrook, L., Murunga, M., Sbrocchi, C., et al. (2021). The future of ocean governance. Rev. Fish Biol. Fish. 2021, 1-18. doi: 10.1007/s11160-020-09631-x

IPCC. (2019). IPCC Special Report on the Ocean and Cryosphere in a Changing Climate. Avaialable Online at: https://www.ipcc.ch/report/srocc/

Ison, S., Pecl, G., Hobday, A. J., Cvitanovic, C., and Van Putten, I. (2021). Stakeholder influence and relationships inform engagement strategies in marine conservation. Ecosyst. People 17, 320-341. doi: 10.1080/26395916.2021. 1938236

Jones, P. J. S., Lieberknecht, L. M. M., and Qiu, W. (2016). Marine spatial planning in reality: Introduction to case studies and discussion of findings. Mar. Policy 71, 256-264. doi: 10.1016/j.marpol.2016.04.026

Jouffray, J.-B., Blasiak, R., Norström, A. V., Österblom, H., and Nyström, M. (2020). The blue acceleration: The trajectory of human expansion into the ocean. One Earth 2, 43-54. doi: 10.1016/J.ONEEAR.2019.12.016 
Kalpazidou Schmidt, E. (2020). Rethinking research funding in pandemic times. Gender Work Organ. 2020:gwao.12601. doi: 10.1111/gwao.12601

Katona, S., Polsenberg, J., Lowndes, J., Halpern, B., Pacheco, E., Mosher, L., et al. (2017). Navigating the seascape of ocean management: waypoints on the voyage toward sustainable use. Seattle, WA: OpenChannels: Forum for Ocean Planning and Management.

Knight, A. T., Cowling, R. M., Rouget, M., Balmford, A., Lombard, A. T., and Campbell, B. M. (2008). Knowing but not doing: Selecting priority conservation areas and the research-implementation gap. Conserv. Biol. 22, 610-617. doi: 10.1111/j.1523-1739.2008.00914.x

Laufer, A. E., and Jones, M. D. (2021). Who pays for marine conservation? Processes and narratives that influence marine funding. Ocean Coast. Manag. 203:105504. doi: 10.1016/j.ocecoaman.2020.105504

Long, R. D., Charles, A., and Stephenson, R. L. (2015). Key principles of marine ecosystem-based management. Mar. Policy 57, 53-60. doi: 10.1016/j.marpol. 2015.01.013

Lundquist, C. J., and Granek, E. F. (2005). Strategies for successful marine conservation: Integrating socioeconomic, political, and scientific factors. Conserv. Biol. 19, 1771-1778. doi: 10.1111/j.1523-1739.2005.00279.x

Lyall, C., Bruce, A., Marsden, W., and Meagher, L. (2013). The role of funding agencies in creating interdisciplinary knowledge. Sci. Public Policy 40, 62-71. doi: $10.1093 / \mathrm{scipol} / \mathrm{scs} 121$

Mach, K. J., Lemos, M. C., Meadow, A. M., Wyborn, C., Klenk, N., Arnott, J. C., et al. (2020). Actionable knowledge and the art of engagement. Curr. Opin. Environ. Sustain. 42, 30-37. doi: 10.1016/j.cosust.2020.01.002

Marine Conservation Institute. (2021). Marine Protection Atlas. Available Online at: https://mpatlas.org/ [Accessed February 27, 2021]

Markus, T., Hillebrand, H., Hornidge, A.-K., Krause, G., and Schlüter, A. (2018). Disciplinary diversity in marine sciences: the urgent case for an integration of research. ICES J. Mar. Sci. 75, 502-509. doi: 10.1093/icesjms/fsx201

McDonald, K. S., Hobday, A. J., Fulton, E. A., and Thompson, P. A. (2018), Interdisciplinary knowledge exchange across scales in a globally changing marine environment. Glob. Chang. Biol. 24:3039. doi: 10.1111/gcb.14168

McKinley, E., and Fletcher, S. (2011). Public Involvement in Marine Management? An Evaluation of Marine Citizenship in the UK. in Littoral 2010 - Adapting to Global Change at the Coast: Leadership, Innovation, and Investment. Les Ulis, France: EDP Sciences.

McLeod, K. L., Lubchenco, J., Palumbi, S. R., and Rosenberg, A. A. (2005). Communication Partnership for Science and the Sea. Scientific Consensus Statement on Marine Ecosystem-Based Management. Available online at: https: //marineplanning.org/wp-content/uploads/2015/07/Consensusstatement.pdf (accessed October 29, 2020).

Mellado, T., Brochier, T., Timor, J., and Vitancurt, J. (2014). Use of local knowledge in marine protected area management. Mar. Policy 44, 390-396. doi: 10.1016/j. marpol.2013.10.004

Merten, W., Reyer, A., Savitz, J., Amos, J., Woods, P., and Sullivan, B. (2016). Global Fishing Watch: Bringing Transparency to Global Commercial Fisheries. Available Online at: http://arxiv.org/abs/1609.08756 (accessed 28 June, 2021).

Neumann, B., Ott, K., and Kenchington, R. (2017). Strong sustainability in coastal areas: a conceptual interpretation of SDG 14. Sustain. Sci. 12, 1019-1035. doi: 10.1007/s11625-017-0472-y

Norström, A. V., Cvitanovic, C., Löf, M. F., West, S., Wyborn, C., Balvanera, P., et al. (2020). Principles for knowledge co-production in sustainability research. Nat. Sustain. 3, 182-190. doi: 10.1038/s41893-019-0448-2

Nursey-Bray, M. J., Vince, J., Scott, M., Haward, M., O’Toole, K., Smith, T., et al. (2014). Science into policy? Discourse, coastal management and knowledge. Environ. Sci. Policy 38, 107-119. doi: 10.1016/j.envsci.2013.10.010

O'Hagan, A. M., Paterson, S., and Le Tissier, M. (2020). Addressing the tangled web of governance mechanisms for land-sea interactions: Assessing implementation challenges across scales. Mar. Policy 112:103715. doi: 10.1016/j.marpol.2019. 103715

Pantò, E. (2019). A game for learning ocean literacy: The responseable project. Int. Inf. Libr. Rev. 51, 247-252. doi: 10.1080/10572317.2019.1629067

Parsons, E. C. M., DellaSala, D. A., and Wright, A. J. (2015). Is marine conservation science becoming irrelevant to policy makers? Front. Mar. Sci. 2:102. doi: 10. 3389/fmars.2015.00102
Pendleton, L., Evans, K., and Visbeck, M. (2020). Opinion: We need a global movement to transform ocean science for a better world. Proc. Natl. Acad. Sci. 117, 9652-9655. doi: 10.1073/pnas.2005485117

Posner, S. M., Fenichel, E. P., McCauley, D. J., Biedenweg, K., Brumbaugh, R. D., Costello, C., et al. (2020). Boundary spanning among research and policy communities to address the emerging industrial revolution in the ocean. Environ. Sci. Policy 104, 73-81. doi: 10.1016/j.envsci.2019.11.004

Queffelec, B., Bonnin, M., Ferreira, B., Bertrand, S., Teles Da Silva, S., Diouf, F., et al. (2021). Marine spatial planning and the risk of ocean grabbing in the tropical Atlantic. ICES J. Mar. Sci. 2021:fsab006. doi: 10. 1093/icesjms/fsab006

Ramesh, R., Chen, Z., Cummins, V., Day, J., D’Elia, C., Dennison, B., et al. (2015). Land-ocean interactions in the coastal zone: past, present $\&$ future. Anthropocene 12, 85-98. doi: 10.1016/j.ancene.2016.01.005

Röckmann, C., van Leeuwen, J., Goldsborough, D., Kraan, M., and Piet, G. (2015). The interaction triangle as a tool for understanding stakeholder interactions in marine ecosystem based management. Mar. Policy 52, 155-162. doi: 10.1016/j. marpol.2014.10.019

Rose, N. A., and Parsons, E. C. M. (2015). Back off, man, I'm a scientist!" When marine conservation science meets policy. Ocean Coast. Manag. 115, 71-76. doi: 10.1016/j.ocecoaman.2015.04.016

Rudolph, T. B., Ruckelshaus, M., Swilling, M., Allison, E. H., Österblom, H., Gelcich, S., et al. (2020). A transition to sustainable ocean governance. Nat. Commun. 11:3600. doi: 10.1038/s41467-020-17410-2

Scanlon, Z. (2018). The art of "not undermining": possibilities within existing architecture to improve environmental protections in areas beyond national jurisdiction. ICES J. Mar. Sci. 75, 405-416. doi: 10. 1093/icesjms/fsx209

Secretariat of the Convention on Biological Diversity. (2020). Global Biodiversity Outlook 5. Montreal: Secretariat of the Convention on Biological Diversity.

Sievanen, L., Campbell, L. M., and Leslie, H. M. (2012). Challenges to interdisciplinary research in ecosystem-based management. Conserv. Biol. 26, 315-323. doi: 10.1111/j.1523-1739.2011.01808.x

Singer, R., and Jones, P. J. S. (2021). Lyme Bay marine protected area: A governance analysis. Mar. Policy 127:103201. doi: 10.1016/J.MARPOL.2018.07.004

Stevens, B., Jolly, C., and Jolliffe, J. (2021). A New Era of Digitalisation for Ocean Sustainability? Preospects, benefits, challenges. Available Online at: http://www. oecd.org/termsandconditions (accessed 28 June, 2021).

Stock, P., and Burton, R. J. F. (2011). Defining terms for integrated (Multi-InterTrans-Disciplinary) sustainability research. Sustainability 3, 1090-1113. doi: $10.3390 /$ su3081090

Stojanovic, T., and Gee, K. (2020). Governance as a framework to theorise and evaluate marine planning. Mar. Policy 120:104115. doi: 10.1016/j.marpol.2020. 104115

Stojanovic, T., Green, D. R., and Lymbery, G. (2010). Approaches to knowledge sharing and capacity building: The role of local information systems in marine and coastal management. Ocean Coast. Manag. 53, 805-815. doi: 10.1016/j. ocecoaman.2010.10.020

Tallis, H., Levin, P. S., Ruckelshaus, M., Lester, S. E., McLeod, K. L., Fluharty, D. L., et al. (2010). The many faces of ecosystem-based management: Making the process work today in real places. Mar. Policy 34, 340-348. doi: 10.1016/j. marpol.2009.08.003

Tanhua, T., Lauvset, S. K., Lange, N., Olsen, A., Álvarez, M., Diggs, S., et al. (2021). A vision for FAIR ocean data products. Commun. Earth Environ. 2:136. doi: 10.1038/s43247-021-00209-4

Tiller, R., De Santo, E., Mendenhall, E., and Nyman, E. (2019). The once and future treaty: Towards a new regime for biodiversity in areas beyond national jurisdiction. Mar. Policy 99, 239-242. doi: 10. 1016/j.marpol.2018.10.046

Tobey, J., Rubinoff, P., Robadue, D., Ricci, G., Volk, R., Furlow, J., et al. (2010). Practicing coastal adaptation to climate change: lessons from integrated coastal management. Coast. Manag. 38, 317-335. doi: 10.1080/08920753.2010.483169

UN. (2021). World Ocean Assessment. New York: United Nations.

UN Environment (2018). The Contributions of Marine and Coastal Area-Based Management Approaches to Sustainable Development Goals and Targets. UN Regional Seas Reports and Studies No. 205. Nairobi: UN Environment. 
UNEP-WCMC, IUCN, and NGS. (2018). Protected Planet Report 2018. Cambridge UK; Gland, Switzerland; and Washington, D.C: UNEP-WCMC, IUCN, and NGS.

Voyer, M., Quirk, G., McIlgorm, A., and Azmi, K. (2018). Shades of blue: what do competing interpretations of the Blue Economy mean for oceans governance? J. Environ. Policy Plan. 20, 595-616. doi: 10. 1080/1523908X.2018.1473153

Weise, H., Auge, H., Baessler, C., Bärlund, I., Bennett, E. M., Berger, U., et al. (2020). Resilience trinity: safeguarding ecosystem functioning and services across three different time horizons and decision contexts. Oikos 129, 445-456. doi: 10.1111/ oik.07213

Winther, J.-G., Dai, M., Rist, T., Hoel, A. H., Li, Y., Trice, A., et al. (2020). Integrated ocean management for a sustainable ocean economy. Nat. Ecol. Evol. 4, 1451-1458. doi: 10.1038/s41559-020-1259-6

Wong-Parodi, G., Mach, K. J., Jagannathan, K., and Sjostrom, K. D. (2020). Insights for developing effective decision support tools for environmental sustainability. Curr. Opin. Environ. Sustain. 42, 52-59. doi: 10.1016/j.cosust.2020.01.005

Wood, C., Solandt, J.-L., Duncan, C., and Lightfoot, P. (2014). Seasearch - a national SCUBA diving project providing evidence for marine conservation and training in marine species identification and survey skills. Pract. Bull. Chart. Inst. Ecol. Environ. Manage. 83, 13-18.
WWF. (2015). Reviving the Ocean Economy: the case for action - 2015. Gland, Switzerland: WWF International.

WWF. (2020). Living Planet Report 2020 - Bending the curve of biodiversity loss. Gland, Switzerland: WWF International.

Conflict of Interest: The authors declare that the research was conducted in the absence of any commercial or financial relationships that could be construed as a potential conflict of interest.

Publisher's Note: All claims expressed in this article are solely those of the authors and do not necessarily represent those of their affiliated organizations, or those of the publisher, the editors and the reviewers. Any product that may be evaluated in this article, or claim that may be made by its manufacturer, is not guaranteed or endorsed by the publisher.

Copyright (C) 2021 Rölfer, Liconti, Prinz and Klöcker. This is an open-access article distributed under the terms of the Creative Commons Attribution License (CC BY). The use, distribution or reproduction in other forums is permitted, provided the original author(s) and the copyright owner(s) are credited and that the original publication in this journal is cited, in accordance with accepted academic practice. No use, distribution or reproduction is permitted which does not comply with these terms. 